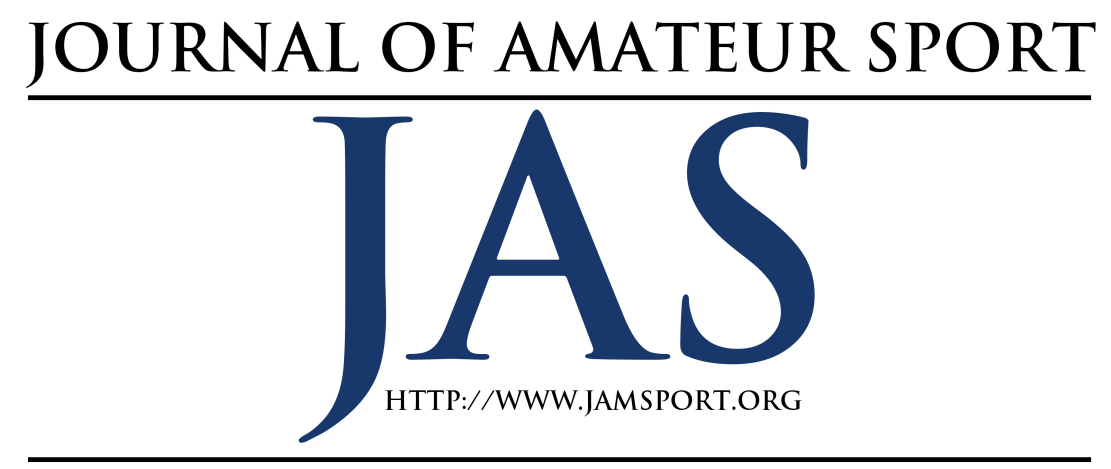

\title{
Sport Transitions as Epiphanies
}

\author{
Randall J. Griffiths ${ }^{1} \quad$ Heather M. Barton-Weston ${ }^{1}$ \\ David W. Walsh ${ }^{2}$
}

${ }^{1}$ University of the Incarnate Word
${ }^{2}$ University of Houston

A basic goal of sport development systems is the transition of athletes from one sport context to another (Green, 2005). Transition research has focused primarily on external transitions in elite athlete's careers at the highest levels of sport (Wylleman \& Lavallee, 2004) rather than prioritizing the internal, cognitive development of the athlete at multiple levels. This study examined the sport transition stories of 48 students from an interpretive framework with the goal of understanding the individual's experience of transition. The disruption stage of these stories represents a time of crisis and transition. Denzin (2001) provided a typology for moments of crisis through four types of epiphanies: major, cumulative, illuminative, and relived. Analysis resulted in all disruptions being coded into one of the four original epiphany types. However, a large number of stories were categorized as major epiphanies. Further inductive coding yielded three sub-types of major epiphanies: major bodily, major life change, and major success. Sport managers will be able to use the results of this study to understand and accommodate the pace and breadth of transition experienced by participants in their sport development systems thus maximizing the retention and advancement to the elite ranks.

S port development systems are often conceptualized as groupings of sport organizations at distinct levels (Green, 2005). The popular concept of the sport pyramid serves as a prime example (Eady,
1993; Green, 2005; Shilbury, Sotiriadou, \& Green, 2008). Entry at the lowest level is characterized by a wide breadth of local, participation-focused sport organizations. Higher levels of the pyramid are 
characterized by narrowing the number of offerings while concurrently raising performance and competitive expectations. While success at any specific level is dependent on factors such as ability, commitment, and motivation, the advancement of an athlete to the highest levels of the system hinges on the successful transition from one level to the next.

Even though system models have allowed sport managers around the world to plan for many athlete transitions (Green \& Oakley, 2001), actual successful transition of athletes remains problematic. Many participants that end their sport involvement will do so at these structural transition points (Bowers, Chalip, \& Green, 2010). Unlike the external structural transitions that can be anticipated and shaped via the rules and processes of the system, the athlete's internal transitions are less predictable. Intuitively we can understand how any misalignment between internal transition and the systemic processes could complicate movement from through the system. Perhaps continuing difficulties with transition are due to our understandings focusing on the external event rather than beginning with the subjective experience of the participant. Internal transitions are not necessarily made at the same time as the external structural transitions of the sport system. Subjectively important experiences could hasten or delay transitions for athletes.

The purpose of this study is to investigate sport transition through the participant's understanding of that transition. The following section will review the current literature on sport transition, how people use stories to understand and recreate their experiences such as transitions, and how Denzin's (2001) epiphany typology may provide a useful means for sport managers to analyze stories about transition and lead to improvement of our sport development systems. This review leads to the final research question: What epiphanies are present in the stories of sport transition?

\section{Literature Review}

Development of an athlete is often seen as the goal of a sport system such as the popular sport pyramid model (Eady, 1993; Green, 2005; Shilbury et al., 2008). This development may come in tandem with movement from one sport context to another. For example, participants may first experience contexts with supportive coaching and opportunities for participants regardless of skill competency at the mass participation level. From this level, the athlete may progress to a competitive sport setting and ultimately to elite sport. These latter contexts favor skill and sport performance over opportunity.

An athlete's participation and advancement through the various contexts of a sport system has been conceived of as an athlete's "career." Research in understanding athlete career transitions in sport has commonly focused on preventing negative transition in order to assist elite 
athletes (e.g., Pearson \& Petitpas, 1990), either transitioning out of/within sport (cf., (Sinclair \& Orlick, 1993; Stambulova, Stephan, \& Japhag, 2007; Wylleman, Alfermann, \& Lavallee, 2004; Wylleman \& Lavallee, 2004) or adjusting to the differences of contextual and structural differences of new competitive levels, often on elite tracks (e.g., Bruner, MunroeChandler, \& Spink, 2008; Debois, Ledon, Argiolas, \& Rosnet, 2012). This work is important as findings have indicated that negative transitions are often associated with detrimental sport participation outcomes from a sport development perspective. Some of these negative (perceived and/or structural) transitions are predictable and normative, such as an end of eligibility or from a choice to retire from competition (Stambulova, 2009; Wylleman \& Lavallee, 2004). Other negative transitions are not predictable, such as a significant injury, and are classified as nonnormative (Wylleman \& Lavallee, 2004). Unexpected transitions are marked with significant difficulty, particularly from the individual perception of the transition itself (Schlossberg, 1981).

While career transition between external contexts is a vital part of athlete development, it forms only part of the development process. The athlete must also cognitively and affectively develop as well. The individual must transition from the perspectives formed in the beginning stages of participation to perspectives useful in continued participation. While the majority of career literature sought to minimize the negative impacts after an external transition via adaptation to those events (cf., Park, Levallee, \& Tod, 2013), participant development does not map directly to external transitions. Chambliss (1989) found that athletes in any competitive context could proactively embrace attitudes that lead to success at elite competitive levels requiring high quality behaviors. These results indicate that the internal work of a transition may come after, during, or before the external transition event within a particular system. Therefore, understanding of any transition event must incorporate the subjectively important internal and external experiences of the individual. Participant stories can provide this unique perspective.

\section{Participant Stories}

Understanding of the experiences of life has been seen as a primary function of the stories people construct (Ricoeur, 2011). Stories about events such as sport transition provide the teller the opportunity to connect subjectively important elements into a coherent plot. This connecting of selected events can result in stories spanning decades with generations of people involved or encompass mere moments with very few characters. While the content of the story is quite open to the individual, narrative structural theorists such as Toderov (1979) and Labov (1972) have identified structural elements appearing in any complete story. While Labov (1972) deconstructed each story into the six parts of abstract, 
orientation, compelling action, resolution, evaluation and coda, Toderov (1979) utilized a less specific structure using the four phases of previous status quo, disruption, action to resolution, and new status quo. The use of narrative analysis has been in a wide range of disciplines including psychology (Bruner, 2002; Polkinghorne, 1995) and education (Clandinin \& Connelly, 2004). The analysis of stories as data centers on the actions of the story explained within the story as a whole. The disruption within the story is seen as an outcome of the story elements and is understood more completely because the entire story is kept in mind. This underlying strength of the narrative perspective is similar to the task of the sport development system and the transitions that take place within it.

While entire stories do highlight the personally impactful events and reactions in the sport transitions of participants, using stories to improve our sport systems requires an analysis that focuses on how the transition aligns with internal development. This analysis can proceed by grouping stories based on the structure and/or content of the stories (Polkinghorne, 1995). Denzin's (2001) epiphany typology provides a guide for examining and grouping the individual's internal development via the moment of realization in transitions.

\section{Epiphanies}

Epiphanies are moments of crisis in which the individual's current status quo is disrupted (Denzin, 1989; 2001). These moments in a subject's life are seen as turning points after which "a person is never the same" (Denzin, 2001, p. 34). This is very similar to adaptation as described by Schlossberg's (1981) transitions to adaptation theory. Denzin (2001) defines four categories of epiphanies: the major, the cumulative, the illuminative, and the relived. The major is a single, significant event that immediately touches every part of the individual's life. The cumulative is an event that is only one of many similar events but becomes a "last straw" that prompts a change. The illuminative is an event that shines light on a previous event that has impacted the status quo but those impacts are manifested in many dissimilar events that follow. Finally, the relived is an event that impacts the individual's life but only later is given larger meanings by the individual as he or she continues to relive the event in memory.

Epiphanies have been examined within a highly diverse range of topics and populations. While epiphanies were originally used to interpret the experiences of battered wives (Cho, 1988) and alcoholics (Denzin, 1987), their use has been extended to other topics including changing leisure options (Carpenter, 2003), dancing careers (Wainwright \& Turner, 2006), and revealing sexual orientation (Thomas, Ross, \& Harris, 2007). In a study that could be argued as exemplary of the most basic level of mass participation sport, Stewart and Smith (2014) examined the experiences of an elderly population with the transition from 
sedentary to regular gym workouts. The range of ages and activity levels of these studies indicate that the use of epiphanies has the ability to examine a more diverse sport population than the elite populations of previous psychology based sport career transition research.

The purpose of the following research is to improve sport development systems by discovering the common experiences of sport transition. Specifically, it will attempt to answer this research question: What epiphanies are present in the stories of sport transition?

\section{Method}

The authors borrowed from narrative analysis to gather the participants' experiences. Narrative analysis is a methodology that allows the story creators to connect subjectively meaningful events together into a story that logically results in the current status quo (Recoeur, 2011; Riessman, 2008). While not intended to follow strict narrative analysis, borrowing the basic story structure (Toderov, 1977) underlying data collection for narrative studies did allow each respondent to select events that he or she had assigned meaning associated with transition. The basic story structure consists of four stages including (1) previous status quo, (2) dismption, (3) action to resolution, and (4) current status quo. Transition events are those experiences that prompt change and development away from the status quo. Given their disruptive nature, transition events align with the narrative concept of a disruption.

\section{Participants}

Sport and exercise stories were collected from students in a mandatory wellness class at a mid-sized, private Catholic university in the southwest. Four sections of the class ( $N=98$ students) were given the mandatory assignment of which 82 completed it. In the final week of the course, instructors distributed informed consent documents and asked the class to return the completed document if they would like to include their completed, graded assignment in the study. Ultimately, 48 students consented to include their sport narratives for analysis. This final group of students included 32 males, 26 females and had an average age of 19. The group's sport participation experience ranged from NCAA Division I athletics to brief, organized youth sport experience.

This final group is representative of the school and the city in which it is located. As a Hispanic Serving Institution that seeks to provide access opportunities to the residents of the county and the seven county that border it, the students closely mirror the population of the city and its surrounding area. The group is predominantly Hispanic with several first generation college students. The gender ratio of the group (male to female ratio of 1.23) does not match the ratios seen in the college (male to female ratio of 0.47 ) or the city (male to female ratio of 0.97 ). 


\section{Instrument}

The narrative assignment consisted of each student completing a four-part worksheet about a significant transition leading to his or her current sport or exercise status quo. The worksheet followed the aforementioned basic narrative construction (Toderov, 1977) of (1) previous status quo, (2) dismption, (3) action to resolution, and (4) current status quo (see appendix A for complete instructions). After completing these four stages, the worksheet prompted the student to further elaborate first on the dismption and secondly on the action to resolution. Students completed the worksheet assignment and submitted the typed, electronic documents to the university's Blackboard course management system.

\section{Analysis}

All participant documents were downloaded from the Blackboard course management system and inspected for completion. Secondly, the researchers removed identifying information and assigned pseudonyms to protect the identity of the respondents. Reliability was maintained through independent coding by two of the authors with discussions between multiple iterations to find agreement over differences in coding (Edwards \& Skinner, 2009).

The initial round of analysis examined the disruption stage as a whole using the pre-determined epiphany types: the major, the cumulative, the illuminative, and the relived (Denzin, 2001). Two of the authors coded the entire set of stories. Choosing the epiphany category for each story was based on the arrangement of contextual and perceptual change from the previous status quo to the new status quo. Recall that epiphanies are distinguished from one another by the arrangement of the perception of change and the contextual change of the individual. These two factors may both change quickly (major), the context may change prior to perceptual change (illuminative), the perception may change prior to the context (cumulative), or the perceptual change may take place long after a change (relived).

The authors also allowed for coding a story as "other" which could account for stories such as those without change across its arc or stories with a perceptual change long before a contextual change (the opposite of relived). However, after the first iteration of coding, neither author had coded any of the sample of stories as "other". Perhaps this was due to the construction of the assignment as a fourpart narrative detailing a change from some previous status quo to a different, current status quo. This structure necessitates both elements, which distinguish the pre-defined set of epiphany types. A less formal story construction prompt may have resulted in generating stories coded as "other".

Over half of the subjects' narratives were coded as major epiphany. Although all of these stories did fit the criteria of a major epiphany, there seemed to be a few noticeable similarities among the impetuses 
of the sudden change. The authors conducted an additional round of inductive analysis on the narratives within the major epiphany group. This additional coding consisted of first using line-by-line coding and then assigning categories that became the subtypes of the major epiphany. Where epiphany types are based on the contextual and perceptual change, subtypes were coded based on the events that drove the transition. Three subtypes of the major type were found: major bodily, major life change, and major success. Additional coding was not conducted on the other three epiphany types in part due to the lower number of stories in these groups. There did not seem to be the differences in transition drivers as was apparent in the larger group of major epiphanies. The following section details the sport elements of the stories within each epiphany type and subtype.

\section{Results}

\section{Major Bodily}

The stories within the major bodily subtype shared a disruption of significant injury, illness, or environmental impact. Recall the major epiphany is one that "shatters a person's life, making it never the same again" (Denzin, 2001, p. 37). These epiphanies have immediate, life changing impact that cannot be ignored. This life changing impact is evident in Sandy's story of an injury as a High School cheerleader when she recounted, "After tearing my ACL, everything changed... not only did my injury disrupt my dancing, it disrupted my entire ability to do anything... For a while, I could not separate myself from my injury." Soccer players with broken ankles, baseball pitchers with torn rotator muscles, and runners with torn patellar tendons are examples of injuries that brought a swift end to participation in sport at the competitive level they had attained. Although they may recover most of their abilities, the injured body did not support the significant work required for competitive sport participation. Mike summarized the permanent impact of these injuries, "The doctor told me this injury is like a death sentence for pitchers. After I had heard this I knew my playing days were over. It was a sad, sad day for me."

Mental and emotional impacts played a large part in these narratives as well. Mary's story deomonstated how self-perception can dominate participation regardless of the body's ability to recover from an injury through her reaction to a knee dislocation. She said, "I just remember thinking how much the pain took over my whole body when I fell to the ground. It traumatized me. I told myself I shouldn't do it anymore. I'd rather be safe than sorry." Participation was ended immediately for Raul not because he developed asthma but because of the depression that followed. He described the quick change, "But when I got asthma I went into a deep depression... I quit swimming completely." The emotional cost was apparent as well, "my heart was broken," (Sally), "my emotions in the hospital were everywhere from being 
depressed to sad..." (Jesse), "as a result I lost my nirvana." (Wendy). The life altering impact of these epiphanies came as a result of physical failure with mental and emotional strain.

\section{Major Life Change}

The major life change subtype contained stories of significant impact due to social and contextual changes in the respondent's life. As with all major epiphanies the impacts of these life changes are immediate and undeniable. Structurally, graduation from high school and entrance into college life impacted several narratives in this subtype. Although the end of high school sport is completely predictable the impact was often greater than anticipated, as Zaina indicated:

Finding my new normal hasn't been very difficult because I didn't really have a choice in the manner. I was no longer in high school so playing softball there wasn't an option anymore. I considered being a walk-on for college but there were many complications.

Along with the shift in context came a change in priorities. Beth's comment succinctly captures the common sentiment from these narratives. She said, "in college sports are different, priorities are different." Where athletes did not continue with varsity athletics in college, stories feature a seismic shift from sport to grades.

A family move also proved to be a major life change for these respondents. Several stories indicated that moving from one location to another caused a sudden shift in sport participation as well. A range of complications resulted from a change in location including a loss of friends, "When I moved...I was forced to find new friends... I lost my passion for sports because my friends did not like sports," (Darlene), change in competitive focus, "I also had to start at a new club team here and realized that club soccer was a lot more competitive [here]" (Laura), and cultural differences as Carlos points out in this comment about how U.S. soccer is different than in his childhood home in Mexico:

Here most of the time [soccer] has [a] schedule and programs to follow. When I was kid we didn't have any day of practice or schedule not even soccer field close to us. We play at [sic.] the street and those things are hard to explain to someone.

Amanda shared how the move can impact many several aspects of life, altering it permanently, "I had a really hard time adjusting to life here. School was a lot harder and softball just felt different."

Finally, a major life change could come about through the actions of a single person in the storyteller's life. Within the sport setting, a loss to a competitor could spur change as it did for Rick. He described the event, "I ran the 100 yard dash and got dead last with a time slower than the JV 100 yard dash runners. My time and placing discouraged me so much that I decided to quit track." Change could also begin with the comments of a demanding coach as 
Lane described, "My coach said he wasn't pleased with my performance... that made me feel like I let down the team." Outside of sport the interactions impacting participation could be quite significant. Gwen succinctly stated why she ended her participation in sport after being molested, "Soccer no longer had the same meaning that it once did." She continued with:

All I wanted to do was quit, isolate myself from every male individual, and eat as much as possible so no male would look at me or make any inappropriate comment about my figure. I didn't care about school, my appearance, my eating habits or my love for this sport.

Stories of life transitions were both positive and negative but for each story, the individual understood that the incident was immediately life changing, sometimes for more than just sport participation.

\section{Major Success}

Stories in the major success subtype feature moments of the sport equivalent of "love at first sight." Disruption in these stories gave the respondent new goals to chase through a new sport to love. Ron's comments typified how these stories highlighted how different their lives were before taking up sport. He said "I was antisocial and did not have many people that I could call friends. I also led a sedentary lifestyle and was not the most motivated person." From these beginnings, each story shared a sudden disruption through experiencing sport. Trevor's experience showed how the new love can impact more than just sport participation. He stated:

Always in trouble and in and out of the principal's office my mother finally let me play football my sixth grade year of school. I discovered I had a gift. My attitude for school immediately changed. Being good in football along with other sports brought me popularity amongst my peers but also with other staff members and authority figures at my school. With that my attitude changed and I was actually bappy [emphasis in original].

The impact of pursuing new goals in sport echoed across their lives.

A significant change in love of sport also came when casual participants had a contextual experience that changed their lives. Nancy came from a family of worldclass athletes but did not hold sport as central to her own life until her first day at the national training center. She described that moment, "[As] soon as I stepped into the buildings, I was in awe. Olympic hopefuls, even Olympians surrounded me as I enter the training facilities. I competed in my first [event] and I was hooked." Vince had a similar experience first as an unaffected middle school runner. He said, "However, when I got into high school, that's when sports really changed my life." The shock of a new context to previously unimportant sport participation altered the centrality of sport in their lives. 
All three of the major epiphany subtypes feature immediate impact radiating beyond sport participation. Whether it comes as a physical injury, a change in neighborhood, or a new passion to pursue, the impact was undeniable and change was unavoidable. Unlike the major epiphany, the following types of cumulative, illuminative, and relived did not carry the same immediate impact. Realization of their impact built over time, sometimes prior to transitions and sometimes as a result of it.

\section{Cumulative}

The stories within the cumulative epiphany type share a history of growing call for action. Recall that in the cumulative epiphany the individual realizes a change is needed after several small events. While the individual may identify one "last straw" event, it is not significantly different from all of the previous events leading up to it. Manuel's experience serves as an example of just how unremarkable this process can be. He described quitting organized soccer after, "the coach put me in only two games the whole season." Unlike major epiphanies with their immediate impact, the stories with the cumulative epiphany type are seemingly undramatic. However, parental pressure to play basketball at a high level show just how dramatic slow building pressure can be. Brad related his story, "I truly hated what my life had become, it was not anything I planned, I felt as though everything that I was doing was for my dad and his own dreams that never developed during his life." Pressure to change was built event by event for these respondents until the moment their perspective changed and with it their sport participation changed as well.

\section{Illuminative}

Stories fitting the illuminative epiphany type build a case that the situation is now different than during the beginning status quo (Denzin, 2001). Where the cumulative epiphany is about realizing that things need to change, the illuminative epiphany is about realizing things have already changed. Will's perception as a star football player didn't change as he became bigger and faster than the other players or even when he became a starter on the varsity team. Although he made some note of these changes, his selfperception didn't change until one final indicator as indicated by this comment: When my coach told me some colleges were in contact with him about me, that's when I knew football was more than a thing to do in high school. I quit the other sports I played and started to lift a lot more and run and practice my skill.

In the extreme, the slow process of an illuminative epiphany can result in significant health troubles. Sara's workouts had increased steadily while eating had fallen to a single meal a day. She said, "As I noticeably began to lose weight my parents began to worry and ask questions. I avoided their questions as long as I could." Even after her family got her help the illuminative 
realization of her situation wasn't immediate as indicated by her comment, "I became more depressed before I began to be happy again." Bart's story of unsustainable level of training echoes Sara's but without the need for family intervention. He summarized with, "My lack of nutritional discipline caused me to have early stages of anemia... [so] I decided to retire from competitive swimming at the age of nineteen." Changes in health, family support, and competitive abilities were each recognized by the individual but did not by itself prompt a change in perspective. Each of these athletes played catch-up with the changes around them.

\section{Relived}

The stories in the relived type look back on an event with developing importance. The relived epiphany is one in which the individual builds up a past event assigning it greater meaning within his or her life. By continuing to focus on this event, the narrator links more outcomes to this single moment. The stories in this type also show how reinterpretation of that significant event is part of its developing importance. The original meaning assigned to the event could change as indicated by Nate in this comment, "One thing I knew I wanted was to be farther away from my parents so they couldn't dictate how I lived." After accomplishing this separation though, Nate realized that it was much different liberation than he had originally thought. He continued, "It took me away from using my dad as a crutch [which] has to be taken away from you for you to realize its worth." Regret is part of the transformation for Teresa's decision not to take a tennis scholarship away from her hometown. She tells what it was like initially, "I would have to leave my boyfriend, which I was in love with at the time. I knew if I were to leave, our relationship was bound to fail." Ultimately, Teresa's narrative is about forgiving herself but not before dropping sports, gaining weight, and mounting stress. She related how things had changed, "I had broken up with my boyfriend at the time. I had turned down the tennis scholarship, because I was in love with him. I started regretting my decision." She begins to load her scholarship decision with greater and greater significance to her current troubles. The disruptive power of relived type epiphanies is unlike the mostly static recollection of events in the other epiphany types. It derives its disruptive power from the transformation and enlarging importance to following events, both positive and negative.

\section{Discussion}

The purpose of this study was to investigate sport transition through the participant's understanding of that tradition. After a review of the literature the following research question remained: What epiphanies are present in the stories of sport transition? Thus, in advancing this line of research we hope to illuminate an understanding on transitional events and 
their potential impacts on both elite and non-elite athletes' sport development.

\section{Implications for Theory}

Denzin's (2001) typology does provide a minimal structure to create similar groups of these sport transition events that disrupted the previous status quo of the respondents. Each of the student narrative disruptions was coded for one of the four types of epiphanies: major, cumulative, illuminative, or relived. However, for this data set of sport stories, the major epiphany type, as originally defined, captured a significant portion of the disruptions. Further sub-categorization was necessary to adequately divide the range of disruptions within the major epiphany type. This categorization resulted in the subtypes of major bodily, major life change, and major success. The utility of epiphanies in interpretive interactionism is its power to reveal an individual's understandings. Denzin (2001) further described the impact of epiphanies, "In these existentially problematic moments, human character is revealed and human lives are shaped, sometimes irrevocably" (p. 145). However, the subtypes of the major epiphany type highlight how discussing both "the structure of these moments and the experiences that flow from them is necessary" (Denzin, 2001, p. 145). The original major type is defined almost exclusively through its immediate and extensive impact. The experiences to follow cannot be fully implied through this general level of definition.
The results of this study indicate that theory based on sport epiphany would need to include the driver of the transition. The sample of sport stories classified as major epiphanies contained three elements that were so significantly present and distinctly previewed the experiences to follow that they challenge a typology based solely on timing and breadth of impact to adequately capture these "existentially problematic moments" (Denzin, 2001, p. 145). The fragility of the body (major bodily), the tenuousness of social context (major life change), and the joy of success (major success) each resonated through the major group and predicted a distinct set of following experiences as to become a requisite, closesecond level of structure to the sport epiphany. This theory must, therefore, be developed through the other three epiphanies to find out what driving events shape and define the sport sub-types of the illuminative, cumulative, and relived epiphanies.

\section{Implications for Practice}

The value to sport development managers in considering any group of epiphanies separately is to focus on the timing and breadth of impact of an event and to examine the nature of these events in relation to structure and policy. For example, stories in the major epiphany are dominated by the suddenness of transition. While the subtype of major success provided the drive to progress to higher levels of sport competition, the other two subtypes 
often resulted in ending sport participation. Transition events in these two major epiphany subtypes often highlight the feeling of quickly moving from in sport to being on the outside. These respondents knew almost immediately that they would never participate in the same way, if ever again. Perhaps the "up or out" nature of the typical sport system (Green, 2005) results in such a large number of events that have an immediate, life altering impact.

Major epiphanies highlight the tenuousness of sport participation and how quickly participation can be stripped from an athlete. Reducing this tenuousness is a possible goal considering sport participation levels have been on the decline (Bowers, et al., 2010). The sport pyramid analogy does allude to an interpretation that as you move up, there are less participants (i.e., up and out). Successfully transitioning back into a lower level of competition seems to be made more problematic based on this assertion. The research may help identify that a major epiphany in someone's sport participation pathway contributes toward this problem.

Several respondents spoke about not being able to participate at the same level as they currently were before the sudden transition typical of the major epiphany. The unspoken statement is that moving down one level of participation more fitting their new abilities is not even an option. For example, Mike's injury was a "death sentence for pitchers". He might be able to throw but never at the level he had attained prior to the injury. Movement to a participatory league or changing his role on the team were never seen as an options. Sport managers hoping to retain players like Mike in the sport would need to proactively build options and support for players with injuries such as his. Having a few examples of players that had successfully transitioned within the sport rather than out of it would provide viable options currently unseen by these participants. Focusing on managing a major epiphany could help sport administrators design better programs to account for this phenomenon.

The practical value to sport development system design of the other three types of epiphanies, cumulative, illuminative, and relived epiphanies, comes from recognizing a transition event over time. Stemming from the unsynchronized changes in perceptual progression and contextual progression experienced by sport participants, stories of these three epiphany types highlight the passage of time in relation to recognizing the impacts of transition events. Recall that the cumulative epiphanies feature a continuing situation, but the realization that it has become untenable and must change is manifest later in a person's life. The illuminative epiphany features a situation that has already changed yet the individual has failed to realize it until later. The relived epiphany also features a look back at a past situational change but concentrates on a single event rather than several as in the illuminative epiphany (Denzin, 2001). Perhaps it is the 
socialization into each context of sport that creates a mentally durable view of the sport setting resistant to change (MacPhail \& Kirk, 2006). Eventually the status quo degraded in each case, sometimes through external transition, ultimately creating the problematic moment of epiphany. One such example is Teresa's relived epiphany, which comes as she connects more and more of her current situation to the decision not to accept a scholarship in favor of young love. It is only as the implications of this decision play out does she begin to attribute much gravity to the transition. Love blinded her but the speed of its removal does not match the slow realizations on her part. Brad's cumulative epiphany comes as he slowly realizes that his basketball participation was solely to satisfy his father. Both of these examples demonstrate the extended period of time in which the participant lives in a mismatched and unsatisfying scenario. Only through the epiphany does either make the moves - internally for Teresa and contextually for Brad - to relieve this tension and develop more rewarding sport participation.

Sport managers could provide participants such as Teresa and Brad opportunities to reflect on their sport decisions and participation as part of their development programs. The difficulty for people experiencing illuminative, cumulative, or relived epiphanies was the period where they did not recognize the disconnect between expectations of the sport situation and their realized experience of it. Helping participants achieve a greater understanding of the transition experience could help the individual complete his or her epiphany, freeing them to move into the action to resolution stage on the way to a new status quo. This process is similar to the adaptation stage of Schlossberg's (1981) model.

Utilizing the epiphany perspective would not necessarily require the creation of entirely new programs. Workshops already exist to assist in adult development and transition (Anderson, Goodman, \& Schlossberg, 2012). For example, several NCAA Division I athletics programs provide developmental support for their athletes with outcome goals tailored to their experience level (e.g. freshmen learn organizational culture and veterans prepare for transition at the end of eligibility). An assessment of the athlete's alignment between perception and situation could easily be added to the participant profile workshop step (Loesch, 1985) to reveal any slow progressing epiphanies and direct support activities helping the student-athlete resolve misalignments undermining important transitions.

Future research should address the limitations of this study while exploring its implications. This study was conducted at a mid-sized catholic university. Although this university does participate in NCAA Division I sports, the overall population of the school may not be diverse enough to adequately represent stories of sport participation. Further, the narrow range of 
ages included in the sample may also have constrained the potential experiences of transition and development in sport. Future research looking into the implications of defining transitions not externally, but through the timing and extent of impact, would also need to utilize a more diverse sample as well.

\section{Conclusions}

This study began with the notion that while an athletic career perspective on transition events provides some valuable directions for helping elite athletes negotiate problematic transitions, solely relying on this perspective provides an incomplete view of development by focusing exclusively on personal adaptation to external transitions. This study examined the transition stories of non-elite sport participants using Denzin's (2001) epiphany typology. We found that grouping the transitions based on epiphanies improved our understanding of these critical events. This understanding comes by illuminating the structure of time and impact in transition events. Given the nature of sport, all participants will experience a transition during their sport experience, some for the positive and others potentially ending sport in his or her life. In fact, these transitions are essential to the development of the participants in our sport systems.

Understanding sport transitions through the lens of epiphanies may allow sport managers to design sport systems that facilitate the primary goals of retention and advancement of athletes throughout their sport development system. Negative transitions often result in ending sport participation. Systems can utilize this new understanding to capture and reintegrate participants experiencing the "up or out" and reintegrate them into sport participation at a more appropriate level. Support may also be designed for those participants experiencing the slower transitions, helping them to complete the transition and continue sport participation without the draining impacts of disruptive events. Transition within sport systems is inevitable but sport managers can account for the timing and impact of these transitions from the participant's perspective may reverse the decline in sport participation around the globe. 


\section{References}

Anderson, M.L., Goodman, J. \& Schlossberg, N.K. (2012). Counseling adults in transition: Linking Schlossberg's theory with practice in a diverse world, 4th Ed. New York: Springer Publishing Company, LLC.

Bowers, M., Chalip, L., \& Green, B.C. (2010). United States of America. In M. Nicholson, R. Hoye, \& B. Houlihan (Eds.), Participation in sport: International policy perspectives (pp. 254 267). New York, NY: Routledge.

Bruner, J. S. (2002). Making Stories: Law, Literature, Life, New York: Farrar, Straus, and Giroux.

Bruner, M.W., Munroe-Chandler, K.J., \& Spink, K.S. (2008). Entry into elite sport: A preliminary investigation into the transition experiences of rookie athletes. Journal of Applied Sport Psychology, 20, 236-252.

Carpenter, G. (2003). Leisure and life perceptions of a mid-life woman experiencing: An epiphany associated with family. World Leisure Journal, 45(4), 44-54.

Chambliss, D. (1989). The mundanity of excellence. Sociological Theory, 7, 70-86.

Cho, J. (1988). Battered wives: Violence and resentment in the Korean family. New York: Aldine de Gruyter.

Clandinin, D. J. \& Connelly, F. M. (2004). Narrative inquiry: Experience and story in qualitative research, San Francisco: Jossey-Bass Publishers.
Denzin, N. (1987). The alcoholic self. Newbury Park, CA: Sage.

Denzin, N. (1989). Interpretive biography. Newbury Park, CA: Sage Publications.

Denzin, N. (2001). Interpretive interactionism (2nd ed.). Thousand Oaks, CA: Sage Publications.

Eady, J. (1993). Practical sports development. London: Pitman

Edwards, A., \& Skinner, J. (2009). Qualitative research in sport management. Burlington, MA: Butterworth-Heinemann.

Green, B.C. (2005). Building sport programs to optimize athlete recruitment, retention, and transition: Toward a normative theory of sport development. Journal of Sport Management, 19, 233-253.

Green, M., \& Oakley, B. (2001). Elite sport development systems and playing to win: Uniformity and diversity in international approaches. Leisure Studies, 20, 247-267. DOI: 10.1080/02614360110103598

Hobfoll, S. E. (1989). Conservation of resources: A new attempt at conceptualizing stress. American Psychologist, 44, 513-524.

Labov, W. (1972). Language in the inner city. Philadelphia: Univ. of Pennsylvania Press.

Loesch, L. C. (1985). Guidelines for conducting workshops. Unpublished manuscript prepared for Continuing Education in Aging for Professional Counselors, a project of the American 
Association of Counseling and

Development.

MacPhail, A., \& Kirk, D. (2006). Young people's socialization into sport: Experiencing the specialising phase. Leisure Studies, 25(1), 57-74. DOI: 10.1080/02614360500116290

Park, S., Lavallee, D., \& Tod, D. (2013). Athletes' career transition out of sport: A systematic review. International Review of Sport and Exercise Psychology, 6, 22-53.

Pearson, R.E., \& Petitpas, A.J. (1990).

Transitions of athletes:

Developmental and preventative perspectives. Journal of Counseling \& Development, 69, 7-10.

Polkinghorne, D. (1995). Narrative configuration in qualitative analysis. In J. A. Hatch (Ed.), Life History and Narrative (pp. 5-23). London:

Routledge Falmer.

Ricoeur, P. (2011). Narrative identity. In D. Wood (Ed.) On Paul Ricoeur: Narrative and Interpretation (pp. 188-200). New York: Routledge

Riessman, C. K. (2008). Narrative Methods for the Human Sciences. Los Angeles: Sage Publications.

Schlossberg, N.K. (1981). A model for analyzing human adaptation to transition. The Counseling Psychologist, 9, 2-18.

doi:10.1177/001100008100900202

Shilbury, D., Sotiriadou, K. P., \& Green, B.

C. (2008). Sport development.

Systems, policies and pathways: An introduction to the special issue. Sport Management Review, 11(3), 217-223.

Sinclair, D. A., \& Orlick, T. (1993). Positive transitions from high-performance sport. The Sport Psychologist, 7, 138150.

Stambulova, N. (2009). Talent development in sport: The perspective of career transitions. In E.Tsung-Min Hung, R. Lidor, \& D. Hackfort (Eds.), Psychology of sport excellence (pp. 6374).Morgantown, WV: Fitness Information Technology.

Stambulova, N., Franck, A., \& Weibull, F. (2012). Assessment of the transition from junior-to-senior sports in Swedish athletes. International Journal of Sport and Exercise Psychology, 10(2), 7995.

Stambulova, N., Stephan, Y., \& Japhag, U. (2007). Athletic retirement: A crossnational comparison of elite French and Swedish athletes. Psychology of Sport and Exercise, 8, 101-118. doi:10.1016/j.psychsport.2006.05.002

Stewart, B., \& Smith, A. C. (2014). The significance of critical incidents in explaining gym use amongst adult populations. Qualitative Research in Sport, Exercise \& Health, 6(1), 45-61.

Thomas, A. B., Ross, M. W., \& Harris, K. K. (2007). Coming out online: Interpretations of young men's stories. Sexuality Research \& Social Policy: A Journal of the NSRC, 4(2), 517. doi:10.1525/srsp.2007.4.2.05 
Toderov, T. (1977). The Poetics of Prose.

Oxford: Blackwell.

Wainwright, S. P., \& Turner, B. S. (2006).

"Just Crumbling to Bits"? An

exploration of the body, Ageing, injury and career in classical ballet dancers. Sociology, 40(2), 237-255.

DOI: $10.1177 / 0038038506062031$

Wylleman, P., \& Lavallee, D. (2004). A

developmental perspective on transitions faced by athletes. In M. Weiss (Ed.), Developmental sport and exercise psychology: A lifespan perspective (pp. 507-527). Morgantown, WV:

Fitness Information Technology.

Wylleman, P., Alfermann, D., \& Lavallee, D. (2004). Career transitions in sport: European perspectives. Psychology of Sport and Exercise, 5, 7-20. doi:

10.1016/S14690292(02)00049-3 


\section{Appendix}

\section{Appendix A: Narrative Worksheet Instructions}

\section{Instructions to students}

Narratives are ways that people understand their experiences in the world. They tell about the changes in our lives leading to where we are today. This reflective writing aims to improve your ability to consciously recognize your narrative about one important topic in your life.

The topics you may choose from are sport or exercise.

- Sport is one of the major social institutions in the modern world. We may engage with it as participants, fans, bystanders, or avoiders. Even if sport is very disliked it does occupy some place in your life.

- Exercise is activity of sufficient intensity to effect change in the body. Just as with sport, exercise will occupy some place in your life such as an active participant, a wishful goal chaser, or even hater of the "gym scene".

Narratives are about change. We are all born neither hating nor liking, neither participating nor avoiding each of these three topics. Along the way each has come to occupy the place in your life that it has today. The place of each may have changed several times during your life; changing subjects, growing or shrinking in importance. The goal is to reflect on how it has come to occupy this place.

Use the attached narrative worksheets to help you construct a narrative about your topic.

Narrative worksheet:

- One way to construct a narrative is to work through the typical four parts of a story; old normal, disruption, action, and new normal. Use the attached narrative worksheet beginning with Part 1 old normal and progress through each part asking yourself "What came next?"

- Another way to construct a narrative is to begin from today and think backward asking yourself "What led to this?", "What events took place before this one to lead to this?" If you choose to work backward then begin with Part 4 New Normal then go to Part 3 etc.

Reflective Writing \#1 focuses on the disruption. After writing short answers to each of the narrative parts (old normal, disruption, action, new normal) you will return to 
the disruption and elaborate on this part of your narrative. Provide greater details on the disruption that ended the previous status quo.

Reflective Writing \#2 focuses on the action. Next you will return to the action part and elaborate on this part of the narrative. Provide greater details on the actions that you took to find the new way of doing things that became your new normal.

\section{Worksheet for Students}

Your Name:

Topic - Choose one of the two topics for your narrative: sport or exercise.

Part 1 Old Normal - Describe the place in your life that sport or exercise had before the place it has today. (It may be more liked or disliked, more or less intense, or connected to different people. The one thing we know is that it is different than today.)

Type your Part 1 here:

Part 2 Disruption - Describe what happened to cause a change in the place of the topic in your life. (Sometimes this is a single, significant event that shatters the old normal. Other times it may be a series of small failures of the old normal that cause you to just "give it up" one day and begin looking for a new way.)

Type your Part 2 here:

Part 3 Action - Describe some of the things that happened while sport or exercise was taking its new place in your life. (Perhaps you tried several new arrangements or had one new thing that took significant time and energy to accomplish.)

Type your Part 3 here:

Part 4 New Normal - Describe the place of sport or exercise in your life today. (Is it very important to you? Do you make decisions for your life based on this sport or exercise? Do you like it or hate it? Is it connected to important people in your life?)

Type your Part 4 here:

Journal of Amateur Sport Volume Two, Issue Two Griffiths et al., 2016 
Elaboration Disruption - Provide more details on what happened to break the old normal. Think of explaining it to a foreigner who may not understand the unspoken meaning of things like someone that grew up in San Antonio would understand them. Help the reader understand why this was disruptive to the old normal. You may include more about your emotions, important people involved, or even other events happening at the same time.

Type your disruption elaboration here:

Elaboration Action - Provide more details on what happened while you were finding and establishing your new normal. Think of explaining it to a foreigner who may not understand the unspoken meaning of things like someone that grew up in San Antonio would understand them. Help the reader understand what you were trying to do at the time. You may include more about your feelings, other people involved, or any number of failed attempts along the way.

Type your action elaboration here: 